\title{
Clinicopathological analysis of 250 cases of pituitary adenoma under the new WHO classification
}

\author{
JIAYU LIU ${ }^{1,2^{*}}$, YUHAO HE $^{3 *}$, XUEBIN ZHANG ${ }^{4 *}$, XIAOLING YAN $^{4}$ and YING HUANG ${ }^{1}$ \\ ${ }^{1}$ Department of Neurosurgery, Tianjin Huanhu Hospital, Tianjin 300000; ${ }^{2}$ Department of Neurosurgery, \\ Peking University People's Hospital, Beijing 100044; ${ }^{3}$ Department of Neurosurgery, Third People's Hospital of Chengdu, \\ Chengdu, Sichuan 610000; ${ }^{4}$ Department of Pathology, Tianjin Huanhu Hospital, Tianjin 300000, P.R. China
}

Received May 22, 2019; Accepted November 13, 2019

DOI: $10.3892 / \mathrm{ol} .2020 .11263$

\begin{abstract}
Pituitary adenomas (PAs) are a common subtype of intracranial tumors. The aim of the present study was to analyse the clinical and pathological features of different types of pituitary adenomas (PAs) according to the 2017 World Health Organisation Endocrine Organ Tumor Classification guidelines. The clinical data of 250 patients with PAs were collected and analysed. Differences in the incidence of invasion, recurrence and apoplexy in patients between high- and low-risk PAs were compared, as were differences in the Ki-67 index between invasive and non-invasive PAs and between recurrent PAs and non-recurrent PAs. Of the 250 cases, 45 cases were diagnosed as somatotroph adenomas, 26 cases as lactotroph adenomas, 1 case as thyrotroph adenoma, 61 cases as corticotroph adenomas, 93 cases as gonadotropin adenomas, 15 cases as null cell adenomas and 9 cases as plurihormonal adenomas. There were 5 types of high-risk pituitary adenoma identified: 17 cases of sparsely granulated somatotroph adenoma, 11 cases of lactotroph adenoma in men, 3 cases of plurihormonal PIT-1 positive adenoma and 42 cases of silent corticotroph adenoma. Crooke's cell adenoma was not identified. High-risk PAs had significantly higher rates of invasion, recurrence and apoplexy compared with that in low-risk types $(\mathrm{P}<0.001)$. Invasive PAs had a significantly higher Ki-67 index compared with that in non-invasive PAs $(3.5 \pm 1.8$ vs. $2.8 \pm 1.3 ; \mathrm{P}<0.01)$. Recurrent PAs had a significantly higher Ki-67 index compared with that in non-recurrent PAs $(3.9 \pm 1.9$ vs. $2.8 \pm 1.3 ; \mathrm{P}<0.001)$. According to the 2017 classification criteria, patients most frequently had gonadotrophin cell adenomas, followed by corticotroph adenomas and the proportion of null cell adenomas was reduced. Differences
\end{abstract}

Correspondence to: Dr Ying Huang, Department of Neurosurgery, Tianjin Huanhu Hospital, 6 Jizhao Road, Tianjin 300000, P.R. China E-mail: yinghuang00@aliyun.com

*Contributed equally

Key words: pituitary adenoma, clinicopathological, invasion, recurrence were noted in the proliferation, recurrence and apoplexy characteristics of high-risk PAs and low-risk PAs. The invasion and recurrence of PAs were found to be related to the Ki-67 index.

\section{Introduction}

In July 2017, the International Agency for Research on Cancer published the new edition of the World Health Organisation (WHO) Endocrine Organ Tumor Classification as an update to the 2004 WHO Endocrine Organ Pathology and Genetic Tumor Classification $(1,2)$. The new edition reflects the latest developments in research in this field over the past 13 years.

The current World Health Organisation (WHO) classification of pituitary neuroendocrine tumours or pituitary adenomas is based on pituitary cell lineages defined by the immunohistochemical expression of anterior pituitary hormones and pituitary specific transcription factors (TFs) in tumour cells (2). The transcription factors regulating differentiation of the hormone producing adenohypophysial cells have been known for a long time (3-7). However, their practical immunohistochemical application has only recently been introduced (2), enabling more precise classification of pituitary neuroendocrine tumours (PitNETs) with sparse or no hormone expression. Pituitary transcription factor 1 (Pit-1) governs the differentiation of somatotroph, lactotroph and thyrotroph cells and is preserved in tumours derived from these cell types (2). T-box family member TBX19 (T-Pit) acts as a TF for corticotroph cells (6) and is a marker of corticotroph pituitary tumours $(8,9)$. Steroidogenic factor 1 (SF-1) determines development of gonadotroph cells (4) and is also expressed in gonadotroph PitNETs (3). By contrast to Pit-1 and T-Pit, which are specific to the anterior pituitary, SF-1 is also active in the adrenal glands and reproductive system (10). Estrogen receptor alpha $(\mathrm{ER} \alpha)$ is other TF not limited to the pituitary gland that influence the differentiation of gonadothroph, lactotroph and thyrotroph cells and are expressed in pituitary tumours originating from these cells (11). According to their expression of adenohypophysial hormones and pituitary-associated transcription factors, Pit -1, SF -1 and T -Pit, PitNETs can be divided into six categories (somatotroph, lactotroph, thyrotroph, corticotroph, gonadotroph and plurihormonal tumours). Each of the tumours may result in metabolic disorders due to hypersecretion of anterior pituitary hormones, or behave as 
non-functioning or hormonally silent tumours, resulting in pituitary insufficiency and/or other symptoms associated with the intrasellar tumour mass (2). However, $\sim 80 \%$ of clinically non-functioning or silent pituitary tumours are of the gonadotroph subtype, expressing follicle stimulating hormone (FSH) and/or luteinising hormone (LH), corticotroph tumours are the second most prevalent and the other hormonal subtypes are rarely reported (12). Hormonally inactive sellar tumours, negative for both anterior pituitary hormones and pituitary-specific TFs, are designated null cell adenomas (2). Occasionally, pituitary tumours are composed of two or even three distinct components, consistent with double or triple adenomas (13).

Pituitary adenoma (PA) is a relatively common intracranial tumour, with the incidence being third only to meningioma and glioma, accounting for $10-16.7 \%$ of all intracranial tumours in an epidemiological study of the UK population $(14,15)$. In autopsy cases, the incidence of PA is 3.2-27\% (15). As PAs occur in the adenohypophysis cells that secrete functional hormones (such as somatotroph, lactotroph, thyrotroph and corticotroph adenomas), the majority of clinical symptoms manifest as endocrine system symptoms (such as acromegaly, amenorrhea, lactation, Cushing's syndrome and hyperthyroidism), and some patients experience compression symptoms (such as hypopituitarism, headache, dizziness and visual field changes) (14). Although PA is a benign tumour, it can show invasive biological characteristics, pituitary apoplexy and recurrence. In the new 2017 edition of the WHO guidelines, PAs and their histological grading were reclassified into adenohypophysis cell lines, which can be diagnosed by pituitary hormones, pituitary-specific transcription factors and immunohistochemistry (IHC) features, without complicated and expensive ultrastructural analysis used in the 2004 edition of the guidelines.

Few studies on the clinical and pathological features of PAs have been conducted using the 2017 WHO classification guidelines (16-18). Therefore the present study retrospectively analysed the clinical and pathological data of 250 patients classified with PAs using the 2017 WHO guidelines, that were surgically resected and confirmed by pathology in Tianjin Huanhu Hospital (Tianjin, China).

\section{Materials and methods}

Patient selection. Patients with a pathologically confirmed diagnosis of PA were identified from the electronic medical records system of Tianjin Huanhu Hospital (Tianjin, China), and those with incomplete clinical and radiological data were excluded. Overall, 250 patients were included, and all underwent surgery between November 2017 and November 2018 in the Department of Neurosurgery in Tianjin Huanhu Hospital. Patient information, such as sex, age at diagnosis, clinical manifestation and relevant medical events was retrospectively collected. Any information that might reveal the identity of the patient was removed before analysis. This study was ethically approved by the Tianjin Huanhu Hospital Ethics Committee of Tianjin Huanhu Hospital, and written informed consent was obtained from each patient prior to the study.

Histopathological evaluation. All biological specimens were sliced into $5 \mu \mathrm{m}$ sections and fixed with formalin (37\%) at $26^{\circ} \mathrm{C}$ and embedded in paraffin for further pathological diagnosis. The block was incubated in an oven at $45^{\circ} \mathrm{C}$ for 20 min to allow complete embedding of the grafted tissue cylinders in the paraffin of the recipient block, and then stored at $4^{\circ} \mathrm{C}$ until microtome sectioning. Tumor slices were verified using routine hematoxylin and eosin (H\&E) staining at $80^{\circ} \mathrm{C}$ for $30 \mathrm{~min}$ and further IHC staining with specific antibodies for follicle-stimulating hormone (FSH; prediluted; cat. no. ZM-0114), luteinizing hormone ( $\mathrm{LH}$; prediluted; cat. no. ZA-0344), thyroid-stimulating hormone (TSH; prediluted; cat. no. ZA-0640), adrenocorticotropic hormone (ACTH; prediluted; cat. no. ZM-0004), growth hormone $(\mathrm{GH}$; prediluted; cat. no. ZA-0531), and prolactin (PRL; prediluted; cat. no. ZA-0596) (all OriGene Technologies, Inc.). The antibodies were incubated at a dilution of $1: 200\left(37^{\circ} \mathrm{C}\right.$ for $\left.2 \mathrm{~h}\right)$. Endogenous peroxidase was inhibited by incubation with freshly prepared $3 \%$ hydrogen peroxide with $0.1 \%$ sodium azide. Tissues were incubated with biotinylated antibodies (prediluted; anti-mouse; cat. no. AP31512BT-N) and horseradish peroxidase (prediluted; anti-mouse; cat. no. AM06196SU-N) at $37^{\circ} \mathrm{C}$ for $1.5 \mathrm{~h}$. Staining was conducted using diaminobenzidine substrate and sections were counterstained with hematoxylin at $37^{\circ} \mathrm{C}$ for $15 \mathrm{~min}$ (all OriGene Technologies, Inc.) Slides were scored by two pathologists who were blinded to the patients' characteristics.

According to the 2017 edition of the WHO guidelines, PAs were categorized into somatotroph, lactotroph, corticotroph, gonadotroph, null cell and plurihormonal adenomas (2). High-risk PA subtypes included sparsely granulated somatotroph adenoma, lactotroph adenoma in men, silent corticotroph adenoma, and Crooke's cell adenoma. For Ki-67 staining, the following methods were used in the present study: Immunohistochemical staining was conducted (as above), and the cells that stained positive for the nuclear antigen Ki-67 (prediluted; cat. no. ZA-0502; OriGene Technologies, Inc.) were visually and quantitatively evaluated under a light microscope (magnification, $\mathrm{x} 400$ ). The Ki-67 percentage score was defined as the percentage of positively-stained tumour cells among the total number of cells assessed (19). Additionally, only positive staining was of interest, independent of the intensity of coloration.

Neuroradiological evaluation. All patients underwent pre- and postoperative magnetic resonance imaging (MRI) using standard 3.0 T scanners, including T1-weighted and T2-weighted $2 \mathrm{~mm}$ sagittal and coronal scans with contrast enhancement. Invasion of the cavernous sinus was notably higher for grades 3 or 4 on the Knosp classification (20). Sphenoid sinus invasion was defined as lesions growing into the sphenoid sinus on preoperative MRI or with visual confirmation during the surgical procedure (21). Therefore, an invasive PA was considered in tumours with cavernous sinus or sphenoid sinus invasion. According to the 2017 edition of the WHO guidelines, the term 'invasive (aggressive)' has been used by clinicians to designate radiologically invasive adenomas, which grow rapidly, tend to recur or progress, and are resistant to combined treatment including surgery and radiation (22). The degree of surgical resection was determined using MRI examinations within 3 days of and at 3 months after the initial surgery. Follow-up MRI was performed annually (or on the return of symptoms) to determine whether there is recurrence. 
Recurrence. MRI of the pituitary for surgical follow-up was performed 6 months after the surgical procedure. Recurrence was defined as progression of a residual tumour or new tumour growth after total resection. Endocrine examinations (1 month, 3 month, 6 months and 1 year postoperatively) were performed to assess the reappearance of hormonal hypersecretion after normalization. Clinical symptoms that were monitored include the reappearance of tumour compression or endocrine symptoms after surgery.

Pituitary apoplexy. Patients were monitored for pituitary apoplexy for two weeks preoperatively via observation of the following: i) Typical clinical symptoms, including severe headaches, nausea and vomiting, and visual disorders; ii) signs of haemorrhage on computed tomography or MRI scans; and iii) intraoperative findings indicative of a haemorrhagic focus in the tumour (23).

Statistical analysis. SPSS v19.0 statistical software (IBM Corp.) was used for data analysis. Data are expressed as the mean \pm standard deviation. The association between the Ki-67 indexes was statistically analysed using the paired Student's t-test. Fisher's exact test was used for comparisons of categorical variables, and paired Student's t-test were used for continuous variables. $\mathrm{P}<0.05$ was considered to indicate a statistically significant difference.

\section{Results}

Patient and tumour characteristics. A total of 250 patients were included, comprising 106 males (42.4\%) and 144 females $(57.6 \%)$, with a male-to-female ratio of $0.74: 1$. The mean age of all patients was $51.71 \pm 12.87$ years, the mean age of the male patients was $52.02 \pm 13.95$ years, and the mean age of the female patients was $51.49 \pm 12.06$ years. The PAs in the present study predominantly manifested as compression symptoms, especially gonadotropin adenomas (80.6\%), corticotroph adenomas (78.8\%) and lactotroph adenomas (69.2\%). Based on the most recent histopathological classification, patients most frequently had gonadotropin adenomas $(n=93$; $37.2 \%)$, followed by corticotroph adenomas $(n=61 ; 24.4 \%)$, somatotroph adenomas $(n=45 ; 18.0 \%)$, lactotroph adenomas $(n=26 ; 10.4 \%)$, null cell adenomas $(n=15$ cases; $6.0 \%)$ and plurihormonal adenomas $(n=9 ; 3.6 \%)$, and one patient had a thyrotroph adenoma $(n=1 ; 0.4 \%)$. Details of each classification and subtype are listed in Tables I-III. Immunohistochemical and Ki-67 staining of different types of pituitary adenoma are exhibited in Figs. 1 and 2.

Sex and age distribution of patients with different types of PAs. In terms of sex distribution, somatotroph adenomas and corticotroph adenomas were observed most often in female patients, while gonadotropin adenomas were mostly observed in male patients. In terms of age distribution, the age groups between 21 and 60 years accounted for $72 \%$ of all patients, and the overall incidence peak of the various types of PAs was between 41 and 60 years. The details are exhibited in Figs. 3 and 4.

Clinical manifestations of different types of PAs. A total of 26 patients $(10.4 \%)$ in the present study exhibited endocrine symptoms (increase or decrease of menstrual blood volume or changes in menstrual cycle, lactation, decreased sexual function and acromegaly), 180 patients (72.0\%) exhibited compressive symptoms (headache, dizziness and decreased vision), 11 patients (4.4\%) exhibited both endocrine symptoms and tumour compression symptoms, and 33 patients (13.2\%) did not exhibit any obvious symptoms. The details are shown in Table IV.

Comparison of the incidence of invasion, recurrence and apoplexy between high-risk and low-risk PAs. A significant difference in the incidence of invasive PAs was found. The incidence of invasive PAs in the high-risk group was higher compared with that in the low-risk group $\left(\chi^{2}=60.627 ; \mathrm{P}<0.001\right)$. In addition, the recurrence rate of high-risk PAs was higher compared with that in low-risk PAs $\left(\chi^{2}=67.903 ; \mathrm{P}<0.001\right)$. Finally, the incidence of pituitary apoplexy was significantly higher in the high-risk group compared with that in the low-risk group $\left(\chi^{2}=38.942 ; \mathrm{P}<0.001\right)$. The details are shown in Table V [WHO Classification of Tumors of Endocrine Organs (2017) clarified 5 high risk pituitary adenomas as: Sparsely granulated somatotroph adenoma (17/250), lactotroph adenoma in men (11/250), plurihormonal PIT-1-positive adenoma (3/250), silent corticotroph adenoma (42/250) and Crooke's cell adenoma (0/250)].

Relationship between invasive and recurrent PAs and the $K i-67$ index. In the present study, there were 37 cases (14.8\%) of invasive PAs and 213 cases $(85.2 \%)$ of non-invasive PAs. The $\mathrm{Ki}-67$ index of the invasive group was significantly higher compared with that in the non-invasive group, $(\mathrm{t}=3.268$; $\mathrm{P}<0.01)$. There were 23 cases $(9.2 \%)$ of recurrent PAs and 213 cases $(90.8 \%)$ of non-recurrent PAs. The Ki-67 index of the recurrent group was significantly higher compared with that in the non-recurrent group $(\mathrm{t}=3.974 ; \mathrm{P}<0.001)$. The details are shown in Tables VI and VII.

\section{Discussion}

In addition to clinical symptoms, serum hormone levels and imaging examinations, the postoperative pathological diagnosis of pituitary tumours is also very important. Histopathology includes histochemical staining and IHC. In 1892, according to H\&E staining, Tapar et al (24) reported that Schoneman divided PAs into chromophobe, eosinophilic, basophilic and mixed pituitary adenomas. Among them, the most common was chromophobe cellular adenoma, accounting for $75-80 \%$ of total PA diagnoses. Unfortunately, these pathological classifications cannot accurately reflect the tumour function (for example, some eosinophilic cell tumours secrete GH and some secrete PRL) (25).

The 2004 edition classified pituitary endocrine tumours into only three categories using the WHO Classification of Tumors (typical adenoma 8272/0, atypical adenoma 8272/1 and pituitary adenoma 8272/3) (25). Hormone-producing adenomas were stratified into subtypes according to their pathological immunoreactivities for the anterior hormones: ACTH, GH, PRL, TSH and FSH/LH (26).

The fourth edition of the WHO classification of tumours of the pituitary gland (2) was published in 2017, bringing 
Table I. Classification of the 250 patients with pituitary adenoma (Percentage of Somatotroph adenomas patients in total male pituitary adenomas).

\begin{tabular}{|c|c|c|c|c|c|c|}
\hline Adenoma subtype & $\begin{array}{c}\text { Total } \\
\text { number, } \mathrm{n}\end{array}$ & $\begin{array}{c}\text { Total } \\
\text { percentage }\end{array}$ & $\begin{array}{l}\text { Number of } \\
\text { Males, } n\end{array}$ & $\begin{array}{l}\text { Percentage of } \\
\text { total males, } \%\end{array}$ & $\begin{array}{l}\text { Number of } \\
\text { females, } n\end{array}$ & $\begin{array}{c}\text { Percentage of } \\
\text { total females }\end{array}$ \\
\hline Somatotroph adenomas & 45 & 18.0 & 15 & $14.2 \%$ & 30 & $20.8 \%$ \\
\hline Densely granulated & 15 & 6.0 & - & - & - & - \\
\hline Sparsely granulated & 17 & 6.8 & - & - & - & - \\
\hline Mixed somatotroph-lactotroph & 13 & 5.2 & - & - & - & - \\
\hline Lactotroph adenomas & 26 & 10.4 & 11 & $10.4 \%$ & 15 & $10.4 \%$ \\
\hline Densely granulated & 19 & 7.6 & - & - & - & - \\
\hline Sparsely granulated & 7 & 2.8 & - & - & - & - \\
\hline Thyrotroph Adenoma & 1 & 0.4 & 0 & 0 & 1 & $0.7 \%$ \\
\hline Corticotroph adenomas & 61 & 24.4 & 5 & $4.7 \%$ & 56 & $38.9 \%$ \\
\hline Gonadotropin adenomas & 93 & 37.2 & 62 & $58.5 \%$ & 31 & $21.5 \%$ \\
\hline Plurihormonal adenomas & 9 & 3.6 & 4 & $3.8 \%$ & 5 & $3.5 \%$ \\
\hline PIT-1 positive & 3 & 1.2 & - & - & - & - \\
\hline Other types & 6 & 2.4 & - & - & - & - \\
\hline Null cell adenoma & 15 & 6.0 & 9 & $8.5 \%$ & 6 & $4.2 \%$ \\
\hline
\end{tabular}

Table II. Distributions of different subtypes of pituitary adenoma as mentioned in the 2017 WHO Endocrine Organ Tumor Classification guidelines.

\begin{tabular}{lccc}
\hline Tumour types & Total number, $n$ & Number of males, $\mathrm{n}$ & Number of females, $\mathrm{n}$ \\
\hline Stationary pituitary adenoma & 50 & 6 & 44 \\
Gonadotropin adenomas & 93 & 62 & 31 \\
Plurihormonal adenomas & 9 & 4 & 5 \\
Null cell adenoma & 15 & 9 & 6 \\
\hline
\end{tabular}

Table III. Distribution of high-risk pituitary adenoma types.

\begin{tabular}{lrrr}
\hline Tumour types & Total number, $\mathrm{n}$ & Number of males, $\mathrm{n}$ & Number of females, $\mathrm{n}$ \\
\hline Sparsely granulated somatotroph adenoma & 17 & 5 & 12 \\
Lactotroph adenoma in men & 11 & 11 & 0 \\
Plurihormonal PIT-1-positive adenoma & 3 & 0 & 3 \\
Silent corticotroph adenoma & 42 & 3 & 39 \\
Crooke's cell adenoma & 0 & 0 & 0
\end{tabular}

several changes to the classification of tumours of the anterior pituitary gland. It introduces a more precise cell lineage-based classification using IHC based on transcription factors and hormones produced. In addition, in this new edition, anterior pituitary tumours and their histological grading are reclassified into adenohypophysis cell lines, which can be diagnosed by pituitary hormones, pituitary-specific transcription factors and standard IHC, without complicated or expensive ultrastructural analysis. For 35-45\% of PAs, the surrounding structure is involved (2). The classification system collectively refers to sparsely granulated somatotroph adenoma, lactotroph adenoma in men, Crooke's cell adenoma, silent corticotroph adenoma, and plurihormonal POU class 1 homeobox 1-positive adenoma as 'invasive adenoma' or 'high-risk adenoma' (12). This type of adenoma grows rapidly, tends to recur or progress and is resistant to surgery and radiotherapy. Silent adenomas are clinically asymptomatic, have low levels of serum hormones and are immunohistochemically positive for certain hormones [thyroid stimulating hormone (TSH) growth hormone $(\mathrm{GH})$ luteinising hormone (LH) prolactin (PRL), adrenocorticotropic hormone (ACTH), follicle stimulating hormone (FSH)] (27). PA with definite metastasis and cerebrospinal cord dissemination is considered a carcinoma. The new edition does not include the term 'atypical adenoma' under pituitary adenoma and no 
A

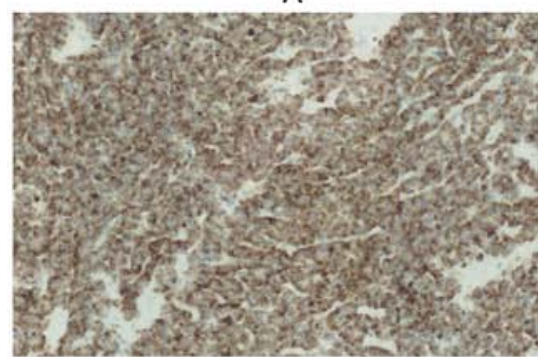

D

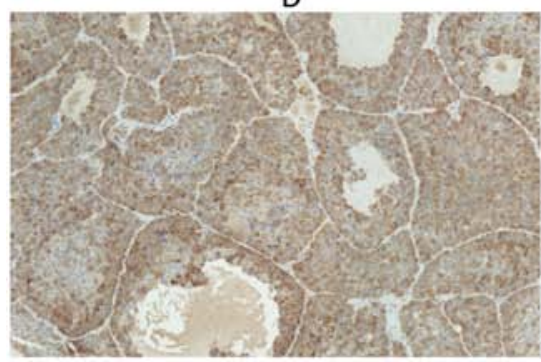

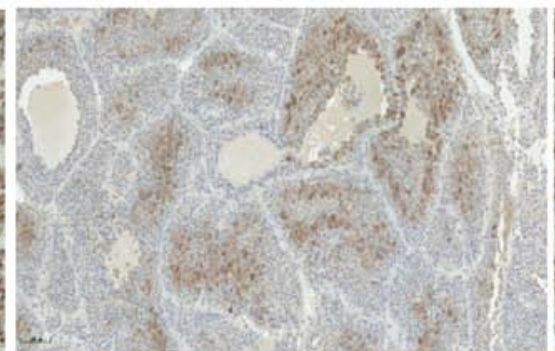

$E$

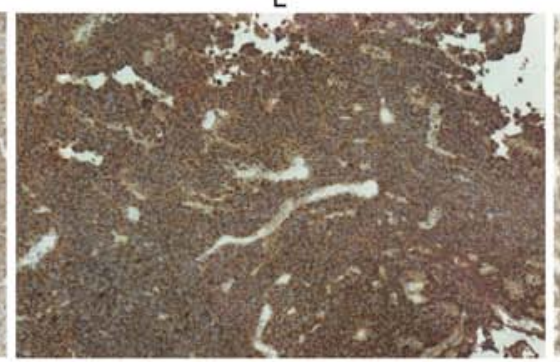

C

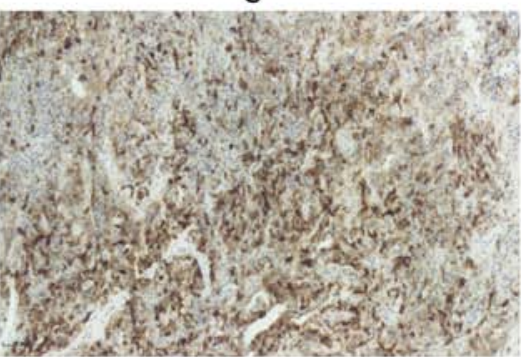

F

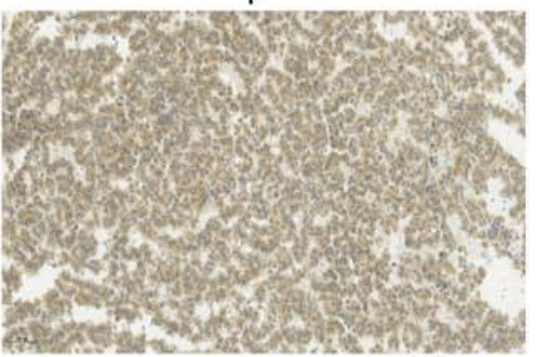

$100 \mu \mathrm{m}$

Figure 1. Immunohistochemical staining of different types of pituitary adenomas. Each image is representative of a different tumour type. Representative images of (A) follicle-stimulating hormone, (B) luteinizing hormone, (C) thyroid-stimulating hormone, (D) adrenocorticotropic hormone, (E) growth hormone and $(\mathrm{F})$ prolactin.

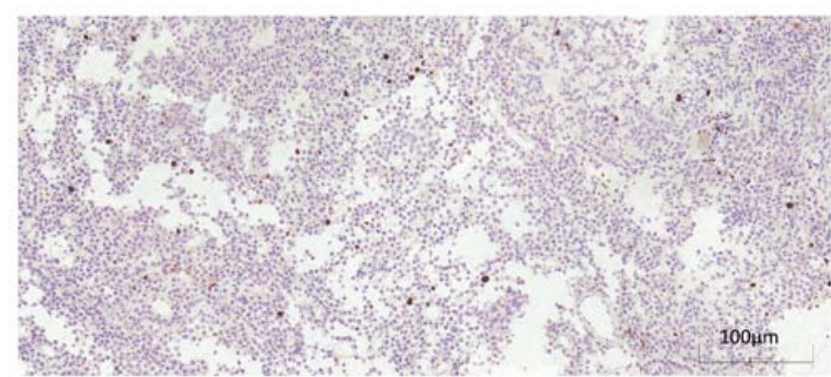

Figure 2. Ki-67 staining was performed on the adrenocorticotropic hormone of pituitary adenoma tissues. The Ki-67 percentage score is defined as the percentage of positively stained tumour cells among the total number of malignant cells assessed. The dark brown stain indicates Ki-67 (+).

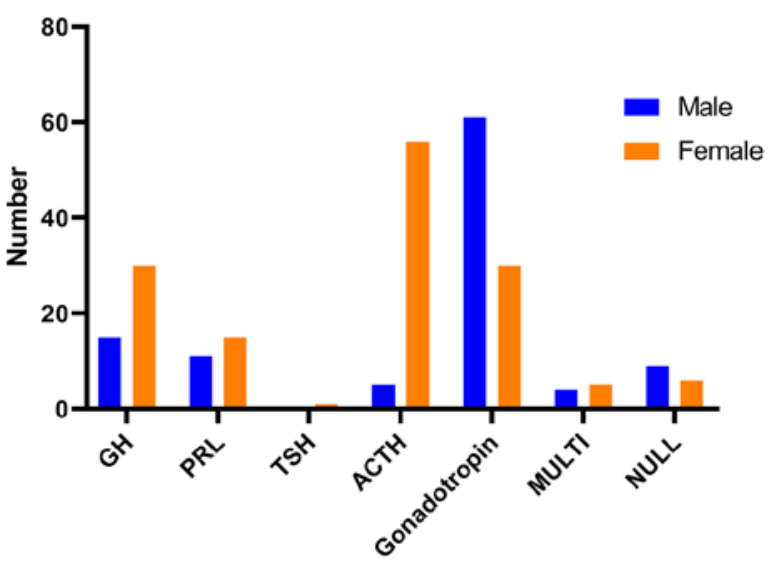

Different types of pituitary adenoma

Figure 3. Sex distribution of patients with different types of pituitary adenomas. somatotroph adenoma and corticotroph adenoma were observed most often in female patients, while gonadotropin adenomas were mostly in male patients. GH, somatotroph adenoma; PRL, lactotroph adenoma; ACTH, corticotroph adenoma; TSH, thyrotroph adenoma; NULL, null cell adenoma; MULTI, plurihormonal adenoma.

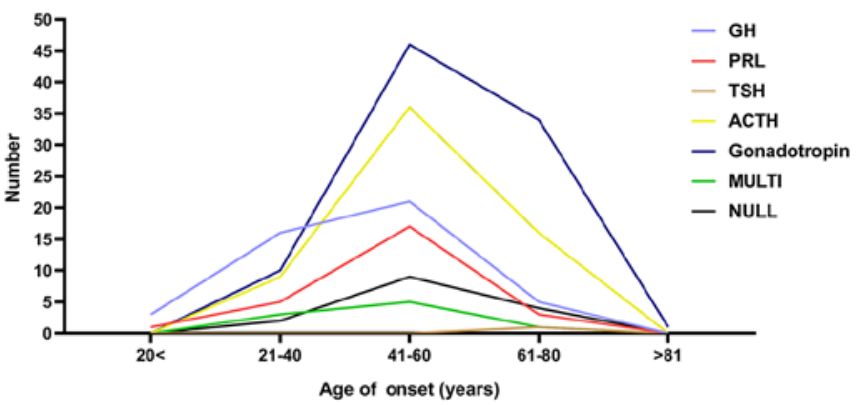

Figure 4. Prevalence of patients with different types of pituitary adenomas in different age groups. The age groups encompassing patients aged between 21 and 60 years old accounted for $72 \%$ of all patients, and the overall peak incidence of different types of pituitary adenoma was between 41 and 60 years old. GH, somatotroph adenoma; PRL, lactotroph adenoma; ACTH, corticotroph adenoma; TSH, thyrotroph adenoma; NULL, null cell adenoma; MULTI, plurihormonal adenoma.

longer recommends the concept of 'hormone-producing pituitary adenoma'. Null cell adenoma was redefined as an adenoma composed of anterior pituitary cells, and IHC, pituitary hormone detection and transcription factor detection showed no evidence of cell-specific differentiation. The present study applies the new classification method to the diagnosis of patients.

The present study retrospectively analysed the clinical and pathological data of 250 patients with PAs using the $2017 \mathrm{WHO}$ classification system. The results showed that the proportion of patients with gonadotropin adenomas was the highest of any subtype, followed by corticotroph adenomas. Moreover, thyrotroph adenoma was found to have the lowest proportion, and the proportion of null cell adenoma was lower compared with that reported previously (28). Although surgical treatment is the first choice for the majority of pituitary tumours, a number of drugs that can be used for the treatment of pituitary tumours are published in the European Guidelines (2018) (29). A consensus 
Table IV. Clinical manifestations of each type of pituitary adenoma.

\begin{tabular}{|c|c|c|c|c|}
\hline Adenoma type & Endocrine symptoms, n (\%) & Tumor mass effects, n (\%) & Both, n (\%) & No symptoms (\%) \\
\hline Somatotroph adenomas & $13(28.9)$ & $22(48.9)$ & $5(11.1)$ & $5(11.1)$ \\
\hline Lactotroph adenomas & $3(11.5)$ & $18(69.2)$ & $0(0.0)$ & $5(19.3)$ \\
\hline Thyrotroph Adenoma & $0(0.0)$ & $1(100)$ & $0(0.0)$ & $0(0.0)$ \\
\hline Corticotroph adenomas & $5(8.2)$ & $48(78.8)$ & $4(6.5)$ & $4(6.5)$ \\
\hline Gonadotropin adenomas & $1(1.1)$ & $75(80.6)$ & $2(2.2)$ & $15(16.1)$ \\
\hline Plurihormonal adenomas & $4(44.4)$ & $5(55.6)$ & $0(0.0)$ & $0(0.0)$ \\
\hline Null cell adenoma & $0(0.0)$ & $11(73.3)$ & $0(0.0)$ & $4(26.7)$ \\
\hline Total & $26(10.4)$ & $180(72)$ & $11(4.4)$ & $33(13.2)$ \\
\hline
\end{tabular}

Table V. Comparison of the incidence of invasion, recurrence and apoplexy between the high- and the low-risk groups.

\begin{tabular}{|c|c|c|c|c|c|c|c|c|c|c|c|c|}
\hline \multirow[b]{2}{*}{ Group } & \multicolumn{4}{|c|}{ Invasion } & \multicolumn{4}{|c|}{ Recurrence } & \multicolumn{4}{|c|}{ Apoplexy } \\
\hline & $\begin{array}{c}\text { Total } \\
\text { number, } \mathrm{n}\end{array}$ & $\%$ & $\chi^{2}$ & P-value & $\begin{array}{c}\text { Total } \\
\text { number, } \mathrm{n}\end{array}$ & $\%$ & $\chi^{2}$ & P-value & $\begin{array}{c}\text { Total } \\
\text { number, } \mathrm{n}\end{array}$ & $\%$ & $\chi^{2}$ & P-value \\
\hline High-risk & 21 & 28.8 & 60.627 & $<0.001$ & 13 & 17.8 & 67.903 & $<0.001$ & 6 & 8.2 & 38.942 & $<0.001$ \\
\hline Low-risk & 16 & 9.0 & - & - & 10 & 5.6 & - & - & 8 & 4.5 & - & - \\
\hline
\end{tabular}

Table VI. Comparison of the Ki-67 index between the invasive and the non-invasive groups.

\begin{tabular}{|c|c|c|c|c|}
\hline \multirow[b]{2}{*}{ Tumour type } & \multicolumn{2}{|c|}{ Group } & \multirow[b]{2}{*}{$\mathrm{t}$} & \multirow[b]{2}{*}{ P-value } \\
\hline & Invasive $(n=37)$ & Non-invasive $(n=213)$ & & \\
\hline Somatotroph adenoma & $6.2 \pm 3.4$ & $2.7 \pm 1.1$ & 4.581 & $<0.001$ \\
\hline Lactotroph adenoma & $3.0 \pm 0.8$ & $2.1 \pm 1.1$ & 1.838 & 0.078 \\
\hline Thyrotroph adenoma & 0.0 & 2.7 & - & - \\
\hline Corticotroph adenoma & $3.6 \pm 1.5$ & $2.7 \pm 1.1$ & 2.068 & 0.043 \\
\hline Gonadotropin & $2.9 \pm 1.1$ & $2.8 \pm 1.1$ & 0.066 & 0.947 \\
\hline Plurihormonal adenoma & $4.2 \pm 1.1$ & $2.6 \pm 1.5$ & 1.409 & 0.202 \\
\hline Null cell adenoma & $4.3 \pm 2.6$ & $3.7 \pm 2.4$ & 0.500 & 0.625 \\
\hline Total & $3.5 \pm 1.8$ & $2.8 \pm 1.3$ & 3.268 & 0.001 \\
\hline
\end{tabular}

Data are presented as the mean \pm SD.

has been reached on the preferred drug therapy for lactotroph adenomas: First-line drugs are dopamine receptor agonists, mainly bromocriptine and cabergoline (26). Drug therapy is also important for the other three types of functional pituitary tumours and for cases in which patients are unable to undergo surgical treatment, are unwilling to undergo surgical treatment, or cannot achieve complete remission after surgery. For somatotroph adenomas, somatostatin analogues are preferred, including octreotide and landrapeptide (26). For corticotroph adenomas, clinical studies have shown that the application of parapeptide in patients with Cushing disease who do not undergo surgery can significantly reduce the level of urinary free cortisol and effectively improve the symptoms of hypercortisolism (30). Somatostatin analogues may also be preferred for patients with thyrotroph adenomas (31). Therefore, it is important to clarify the pathological properties of pituitary tumours for the drug treatment of patients with pituitary tumours. A previous study revealed that null cell adenomas, somatotroph adenomas and lactotroph adenomas are more common $(\mathrm{P}<0.01)(32)$. As the 2017 classification standard was adopted in the current study, the number of cases of gonadotropin adenoma and corticotroph adenoma was increased due to the recognition of partially stationary PAs in non-functional adenomas. The classification of PAs in the 2004 edition of the WHO guidelines mainly used the cellular morphology of tumour tissues, intracellular hormone secretory components and ultrastructural electron microscopy to classify PAs. However, using the 2004 WHO Classification of Tumors were prone to misdiagnose non-functional PAs, 
Table VII. Comparison of the Ki-67 index between the recurrence and the non-recurrence group.

\begin{tabular}{lcccr}
\hline & \multicolumn{3}{c}{ Group } & \\
\cline { 2 - 5 } Tumour type & Recurrent $(\mathrm{n}=23)$ & Non-recurrent $(\mathrm{n}=227)$ & $\mathrm{t}$ & P-value \\
\hline Somatotroph adenoma & $4.4 \pm 1.2$ & $2.8 \pm 1.5$ & 1.816 & 0.076 \\
Lactotroph adenoma & $1.5 \pm 1.3$ & $2.4 \pm 1.1$ & -1.079 & 0.291 \\
Thyrotroph adenoma & 0.0 & 2.7 & - & - \\
Corticotroph adenoma & $3.6 \pm 1.5$ & $2.8 \pm 1.2$ & 1.575 & 0.120 \\
Gonadotropin & $3.9 \pm 1.4$ & $2.7 \pm 1.1$ & 2.783 & 0.007 \\
Plurihormonal adenoma & 5.0 & $2.7 \pm 1.4$ & 1.504 & 0.176 \\
Null cell adenoma & 10.0 & $3.7 \pm 1.9$ & 3.263 & 0.006 \\
Total & $3.9 \pm 1.9$ & $2.8 \pm 1.3$ & 3.974 & $<0.001$ \\
\hline
\end{tabular}

especially for null cell adenomas. If the pituitary hormone immunohistochemistry staining is negative, a tumour may be diagnosed as null cell adenoma. However, some null cell adenomas were weakly expressed in focal subunits or do not secrete other hormones (TSH, GH, LH, PRL, FSH and ACTH), and most of the hormone-negative adenomas were derived from differentiated adenohypophysis cells by staining with associated transcription factors (PIT-1, ER $\alpha$, T-PIT and SF-1) (33). In addition, according to the 2004 WHO classification of Endocrine Organ Pathology and Genetic Tumours, 30\% of tumours can be diagnosed as null cell adenomas. However, using the 2017 edition, $<5 \%$ of adenomas are diagnosed as null cell adenomas. In the present study, there were only 15 cases of null cell adenoma, accounting for $6 \%$ of the total cases, which was consistent with a previous report using the 2017 classification system (2). Therefore, we hypothesize that the 2004 classification standard increased the diagnostic rate of null cell adenoma, resulting in a lower diagnostic rate of other non-functional adenomas.

The PAs in the present study mainly manifested as compression symptoms. All PAs of different pathological types showed clinical manifestations caused by tumour compression, especially gonadotropin adenomas (80.6\%), corticotroph adenomas (78.8\%), and lactotroph adenomas (69.2\%). The majority of the patients with endocrine symptoms were women; the clinical symptoms (menstrual changes and galactorrhoea) caused by hormonal changes may be more obvious in women, and most of them can be detected and treated immediately. In men, however, there are often no obvious clinical symptoms, so the tumour is not diagnosed until compression symptoms are noted.

In addition, female patients account for the majority of somatotroph adenomas and corticotroph adenomas, while male patients account for the majority of gonadotropin adenomas in the present study. This finding is consistent with a previous study using the 2004 classification system (34), which suggests that some types of PAs are significantly associated with sex. The number of patients in the 21-60 years age groups was the highest, and the incidence was the highest in the 41-60 years age group. As previously reported, the prevalence of PAs increases with age, and the peak age of diagnosis is $30-60$ years (35).

The 2017 classification system removed the diagnosis of 'atypical PAs' and explicitly proposed five types of 'high-risk PAs', suggesting that these five subtypes are likely to have a poorer prognosis (36). At present, there is a lack of specific diagnostic criteria for aggressive pituitary tumors, which is considered only a clinical combination of various pituitary tumours showing refractory behaviour. In the present study, the proportion of invasive adenomas in high-risk PAs reached $28.8 \%$, the recurrence rate was $17.8 \%$, and the incidence of apoplexy was $8.2 \%$. The results showed that the incidence of invasion, recurrence and apoplexy of high-risk PAs was higher compared with that in non-high-risk PAs. This finding indicates that these specific types of adenomas have more inherent biological characteristics of highly invasive behaviour, high risk of recurrence and apoplexy, and neurosurgeons should attach great importance to the diagnosis of these adenomas. In a European study, Crooke's cell adenoma is a subtype of high-risk PA, which is very rare and accounts for $>1 \%$ of Pas (37); it was not identified in the present study.

Currently, surgery is still the preferred treatment for invasive PAs. However, due to the similar malignant biological behaviour, total surgical resection of invasive PAs is difficult; the rate of total resection is lower compared with that of non-invasive tumours, and the postoperative recurrence rate is higher, requiring multiple surgical treatments (38). Thus, patients with invasive PAs often need adjuvant drug treatment. Although the WHO guidelines do not currently include invasive tumours in the PAs classification, the 2017 classification also emphasizes that invasive adenoma can be used as an important feature for identifying clinically refractory adenomas and determining prognosis. Invasive growth can be identified using preoperative MRI and intraoperative findings of tumour spread to the dura mater, bone or nasal mucosa (39). The relationship between the invasion of PAs and the Ki-67 index has also been discussed in different ways (40). It has been postulated that there is no relationship between invasiveness and a high Ki-67 index (41). The results of the present study indicated that the $\mathrm{Ki}-67$ index was related to the invasion and recurrence of PAs. Invasive PAs have a higher Ki-67 index, and the differences in the $\mathrm{Ki}-67$ index between the invasive group and the non-invasive group in somatotroph adenomas and corticotroph adenomas are statistically significant. It is suggested that the Ki-67 index can objectively reflect the proliferation potential of PAs and has good clinical value in predicting the invasion of Pas (42). There were statistically significant differences 
in the Ki-67 index between the recurrent group and the non-recurrent group in gonadotropin adenoma and null cell adenoma. It is suggested that the Ki-67 index has a certain guiding significance in predicting the prognosis of patients to evaluate the tendency of tumour recurrence after surgery by reflecting the number of proliferating tumour cells (43). According to the Ki-67 index of postoperative pathological diagnosis, combined with preoperative imaging findings and intraoperative findings, the individualized selection of postoperative treatment options is conducive to the postoperative recovery of patients with invasive pituitary tumours, reducing postoperative hormone abnormalities, delaying tumour recurrence and improving the quality of life of patients (44-46).

However, the present study has several limitations. The follow-up period was too short to detect the reported recurrences, despite using the 2017 WHO classification standard. In addition, a further case follow-up study is currently being performed and the results of which will be published in the near future. The numbers of invasive pituitary adenomas of each subtype were small, thus the results may not reflect the effect of Ki-67 on the invasiveness of pituitary adenomas in each subtype. For example, the sample size of invasive pituitary adenoma in the TSH and PRL groups was $>5$. Therefore, future studies should include a higher number of invasive pituitary adenomas for each subtype, to ensure more reliable data.

Furthermore analysis focusing on categorising tumours based on functional compared with non-functional tumours was not performed. Further research is needed to explore why many functional pituitary adenomas do not have the endocrine symptoms, invasiveness and recurrence of other subgroups.

In conclusion, the new 2017 classification is practical and reasonable from both a molecular and clinical pathology perspective, as this classification is based on IHC studies of transcription factors, which are intuitively understandable and are technically and diagnostically helpful (26). The present study is not the first clinicopathological analysis of pituitary adenomas based on the new classification (26,47-50), however previous studies have also showed that the new WHO 2017 classification categorizes less null cell adenomas compared with previous classifications $(26,47)$. In the present study, patients with pituitary tumour diagnosed after 2017 were systematically classified according to the 2017 classification criteria and provides a theoretical basis for the accurate diagnosis of PAs. An accurate understanding and application of the latest classification system will contribute to better clinical diagnosis and treatment as well as advanced prediction of tumour outcomes and patient prognosis. Although the number of cases in the present study is not sufficiently large, the new classification should be further analysed and used in combination with clinical practice in the future.

\section{Acknowledgements}

Not applicable.

\section{Funding}

No funding was received.

\section{Availability of data and materials}

The datasets used and/or analysed during the present study are available from the corresponding author upon reasonable request.

\section{Authors' contributions}

JL and YH made substantial contributions to the conception and design of the work, drafting the work and revising it critically for important intellectual content, final approval of the version to be published and agreement to be accountable for all aspects of the work. YHH, XZ and XY contributed to the acquisition, analysis and interpretation of data for the work, drafting the work and revising it critically for important intellectual content, and also gave final approval of the version to be published and agreement to be accountable for all aspects of the work.

\section{Ethics approval and consent to participate}

The present study was approved by the Medical Ethics Committee of Tianjin Huanhu Hospital, and all patients provided written informed consent to participate.

\section{Patient consent for publication}

Not applicable.

\section{Competing interests}

The authors declare that they have no competing interests.

\section{References}

1. Kovacs K: The 2004 WHO classification of pituitary tumors: Comments. Acta Neuropathol 111: 62-63, 2006.

2. Lopes MBS: The 2017 world health organization classification of tumors of the pituitary gland: A summary. Acta Neuropathol 134: 521-535, 2017.

3. Asa SL, Bamberger AM, Cao B, Wong M, Parker KL and Ezzat S: The transcription activator steroidogenic factor-1 is preferentially expressed in the human pituitary gonadotroph. J Clin Endocrinol Metab 81: 2165-2170, 1996.

4. Lee SL, Sadovsky Y, Swirnoff AH, Polish JA, Goda P, Gavrilina $G$ and Milbrandt J: Luteinizing hormone deficiency and female infertility in mice lacking the transcription factor NGFI-A (Egr-1). Science 273: 1219-1221, 1996.

5. Zhao L, Bakke M, Krimkevich Y, Cushman LJ, Parlow AF, Camper SA and Parker KL: Steroidogenic factor 1 (SF1) is essential for pituitary gonadotrope function. Development 128: 147-154, 2001.

6. Lamolet B, Pulichino AM, Lamonerie T, Gauthier Y, Brue T, Enjalbert A and Drouin J: A pituitary cell-restricted T box factor, Tpit, activates POMC transcription in cooperation with Pitx homeoproteins. Cell 104: 849-859, 2001.

7. Scully KM and Rosenfeld MG: Pituitary development: Regulatory codes in mammalian organogenesis. Science 295: 2231-2235, 2002

8. Vallette-Kasic S, Figarella-Branger D, Grino M, Pulichino AM, Dufour H, Grisoli F, Enjalbert A, Drouin J and Brue T: Differential regulation of proopiomelanocortin and pituitary-restricted transcription factor (TPIT), a new marker of normal and adenomatous human corticotrophs. J Clin Endocrinol Metab 88: 3050-3056, 2003.

9. Sjöstedt E, Bollerslev J, Mulder J, Lindskog C, Pontén F and Casar-Borota O: A specific antibody to detect transcription factor T-Pit: A reliable marker of corticotroph cell differentiation and a tool to improve the classification of pituitary neuroendocrine tumours. Acta Neuropathol 134: 675-677, 2017. 
10. Luo X, Ikeda Y and Parker KL: A cell-specific nuclear receptor is essential for adrenal and gonadal development and sexual differentiation. Cell 77: 481-490, 1994.

11. Dasen JS, O'Connell SM, Flynn SE, Treier M, Gleiberman AS Szeto DP, Hooshmand F, Aggarwal AK and Rosenfeld MG: Reciprocal interactions of Pit1 and GATA2 mediate signaling gradient-induced determination of pituitary cell types. Cell 97: 587-598, 1999.

12. Manojlovic-Gacic E, Engstrom BE and Casar-Borota O: Histopathological classification of non-functioning pituitary neuroendocrine tumors. Pituitary 21: 119-129, 2018.

13. Kontogeorgos G, Scheithauer BW, Horvath E, Kovacs K, Lloyd RV, Smyth HS and Rologis D: Double adenomas of the pituitary: A clinicopathological study of 11 tumors. Neurosurgery 31: 840-849, 1992.

14. Raappana A, Koivukangas J, Ebeling T and Pirilä T: Incidence of pituitary adenomas in northern Finland in 1992-2007. J Clin Endocrinol Metab 95: 4268-4275, 2010.

15. Buurman H and Saeger W: Subclinical adenomas in postmortem pituitaries: Classification and correlations to clinical data. Eur J Endocrinol 154: 753-758, 2006.

16. Eremkina AK, Dzeranova LK, Pigarova EK, Mokrysheva NG and Dedov II: Morphofunctional features of non-functioning pituitary adenomas. Arkh Patol 81: 71-78, 2019 (In Russian).

17. García-Sáenz M, Uribe-Cortés D, González-Virla B, Mendoza-Zubieta V and Vargas-Ortega G: Silent pituitary plurihormonal adenoma: Clinical relevance of immunohistochemical analysis. Rev Med Inst Mex Seguro Soc 57: 48-55, 2019 (In English and Spanish).

18. Pappy AL II, Savinkina A, Bicknese C, Neill S, Oyesiku NM and Ioachimescu AG: Predictive modeling for pituitary adenomas: Single center experience in 501 consecutive patients. Pituitary 22 520-531, 2019

19. Liu J, Zhang X, Yan X, Sun M, Fan Y and Huang Y: Significance of TERT and ATRX mutations in glioma. Oncol Lett 17: 95-102, 2019.

20. Micko AS, Wohrer A, Wolfsberger S and Knosp E: Invasion of the cavernous sinus space in pituitary adenomas: Endoscopic verification and its correlation with an MRI-based classification. J Neurosurg 122: 803-811, 2015.

21. Andujar-Plata P, Villar-Taibo R, Ballesteros-Pomar MD, Vidal-Casariego A, Pérez-Corral B, Cabezas-Agrícola JM, Álvarez-Vázquez P, Serramito R and Bernabeu I: Long-term outcome of multimodal therapy for giant prolactinomas. Endocrine 55: 231-238, 2017.

22. Chatzellis E, Alexandraki KI, Androulakis II and Kaltsas G: Aggressive pituitary tumors. Neuroendocrinology 101: 87-104, 2015.

23. Mou C, Han T, Zhao H, Wang S and Qu Y: Clinical features and immunohistochemical changes of pituitary apoplexy. J Clin Neurosci 16: 64-68, 2009.

24. Tapar K, Kovach K and Khorvat E: Classification, pathology and molecular biology of pituitary adenoma. Arkh Patol 59: 7-17, 1997 (In Russian).

25. Klimstra DS: Pathology reporting of neuroendocrine tumors: Essential elements for accurate diagnosis, classification, and staging. Semin Oncol 40: 23-36, 2013.

26. Inoshita $\mathrm{N}$ and Nishioka $\mathrm{H}$ : The $2017 \mathrm{WHO}$ classification of pituitary adenoma: Overview and comments. Brain Tumor Pathol 35: $51-56,2018$.

27. Cooper $\mathrm{O}$ and Melmed S: Subclinical hyperfunctioning pituitary adenomas: The silent tumors. Best Pract Res Clin Endocrinol Metab 26: 447-460, 2012

28. Chalkley MD, Kiupel M and Draper AC: Pituitary null cell adenoma in a domestic llama (Lama glama). J Comp Pathol 151: 51-56, 2014.

29. Raverot G, Burman P, McCormack A, Heaney A, Petersenn S, Popovic V, Trouillas J and Dekkers OM; European Society of En docrinology: European society of endocrinology clinical practice guidelines for the management of aggressive pituitary tumours and carcinomas. Eur J Endocrinol 178: G1-G24, 2018.

30. Colao A, Petersenn S, Newell-Price J, Findling JW, Gu F, Maldonado M, Schoenherr U, Mills D, Salgado LR and Biller BM Pasireotide B2305 Study Group: A 12-month phase 3 study of pasireotide in Cushing's disease. N Engl J Med 366: 914-924, 2012.

31. Yamada S, Fukuhara N, Horiguchi K, Yamaguchi-Okada M, Nishioka H, Takeshita A, Takeuchi Y, Ito J and Inoshita N: Clinicopathological characteristics and therapeutic outcomes in thyrotropin-secreting pituitary adenomas: A single-center study of 90 cases. J Neurosurg 121: 1462-1473, 2014.

32. Mortini P, Losa M, Barzaghi R, Boari N and Giovanelli M: Results of transsphenoidal surgery in a large series of patients with pituitary adenoma. Neurosurgery 56: 1222-1233, 2005.
33. Nishioka $\mathrm{H}$, Inoshita $\mathrm{N}$, Mete $\mathrm{O}$, Asa SL, Hayashi K, Takeshita A, Fukuhara N, Yamaguchi-Okada M, Takeuchi Y and Yamada S: The complementary role of transcription factors in the accurate diagnosis of clinically nonfunctioning pituitary adenomas. Endocr Pathol 26: 349-355, 2015.

34. Arafah BM and Nasrallah MP: Pituitary tumors: Pathophysiology, clinical manifestations and management. Endocr Relat Cancer 8: 287-305, 2001.

35. Agustsson TT, Baldvinsdottir T, Jonasson JG, Olafsdottir E, Steinthorsdottir V, Sigurdsson G, Thorsson AV, Carroll PV, Korbonits $\mathrm{M}$ and Benediktsson R: The epidemiology of pituitary adenomas in Iceland, 1955-2012: A nationwide population-based study. Eur J Endocrinol 173: 655-664, 2015.

36. Mete O, Gomez-Hernandez K, Kucharczyk W, Ridout R, Zadeh G, Gentili F, Ezzat S and Asa SL: Silent subtype 3 pituitary adenomas are not always silent and represent poorly differentiated monomorphous plurihormonal Pit-1 lineage adenomas. Mod Pathol 29: 131-142, 2016.

37. Manojlovic-Gacic E, Bollerslev J and Casar-Borota O: Invited Review: Pathology of pituitary neuroendocrine tumours: Present status, modern diagnostic approach, controversies and future perspectives from a neuropathological and clinical standpoint. Neuropathol Appl Neurobiol 2019.

38. Dworakowska D and Grossman AB: Aggressive and malignant pituitary tumours: State-of-the-art. Endocr Relat Cancer 25 R559-R575, 2018.

39. Sav A, Rotondo F, Syro LV, Di Ieva A, Cusimano MD and Kovacs K: Invasive, atypical and aggressive pituitary adenomas and carcinomas. Endocrinol Metab Clin North Am 44: 99-104, 2015.

40. Pizarro CB, Oliveira MC, Coutinho LB and Ferreira NP: Measurement of Ki-67 antigen in 159 pituitary adenomas using the MIB-1 monoclonal antibody. Braz J Med Biol Res 37: 235-243, 2004

41. Honegger J, Prettin C, Feuerhake F, Petrick M, Schulte-Mönting J and Reincke M: Expression of Ki-67 antigen in nonfunctioning pituitary adenomas: Correlation with growth velocity and invasiveness. J Neurosurg 99: 674-679, 2003.

42. Marques P, Mafra M, Calado C, Martins A, Monteiro J and Leite V: Aggressive pituitary lesion with a remarkably high Ki-67. Arq Bras Endocrinol Metabol 58: 656-660, 2014.

43. Del Basso De Caro M, Solari D, Pagliuca F, Villa A, Guadagno E, Cavallo LM, Colao A, Pettinato G and Cappabianca P: Atypical pituitary adenomas: Clinical characteristics and role of ki-67 and p53 in prognostic and therapeutic evaluation. A series of 50 patients. Neurosurg Rev 40: 105-114, 2017.

44. Klibanski A: Clinical practice. Prolactinomas. N Engl J Med 362: 1219-1226, 2010

45. Sheehan J, Rainey J, Nguyen J, Grimsdale R and Han S: Temozolomide-induced inhibition of pituitary adenoma cells. J Neurosurg 114: 354-358, 2011.

46. Chen XY, Wang Z, Li B, Zhang YJ and Li YY: Pim-3 contributes to radioresistance through regulation of the cell cycle and DNA damage repair in pancreatic cancer cells. Biochem Biophys Res Commun 473: 296-302, 2016.

47. Batista RL, Trarbach EB, Marques MD, Cescato VA, da Silva GO, Herkenhoff CGB, Cunha-Neto MB and Musolino NR: Nonfunctioning pituitary adenoma recurrence and its relationship with sex, size, and hormonal immunohistochemical profile. World Neurosurg 120: e241-e246, 2018

48. Lee JYK, Cho SS, Zeh R, Pierce JT, Martinez-Lage M, Adappa ND, Palmer JN, Newman JG, Learned KO, White C, et al: Folate receptor overexpression can be visualized in real time during pituitary adenoma endoscopic transsphenoidal surgery with near-infrared imaging. J Neurosurg 129: 390-403, 2018

49. Mitrofanova LB, Vorobeva OM and Gorshkov AN: Analysis of pituitary adenoma expression patterns suggests a potential role for the NeuroD1 transcription factor in neuroendocrine tumor-targeting therapies. Oncotarget 10: 289-312, 2019.

50. Wang S, Ding C, Xiao D, Wu Z and Wei L: Evaluation of a novel general pituitary hormone score to evaluate the function of the residual anterior pituitary (adenohypophysis) in patients following surgery for pituitary adenoma. Med Sci Monit 24: 7944-7951, 2018

This work is licensed under a Creative Commons Attribution-NonCommercial-NoDerivatives 4.0 International (CC BY-NC-ND 4.0) License. 